\title{
CUESTIONES SOBRE LA REFORMA CONSTITUCIONAL
}

\author{
Rafael Escudero Alday \\ Universidad Carlos III de Madrid
}

\section{LAS DOS VÍAS PARA LA REFORMA DE LA CONSTITUCIÓN}

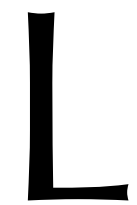

a reforma constitucional es un tema de moda en España ${ }^{1}$. Tanto en sede política como académica se suceden debates acerca de la necesidad o no de reformar la Constitución de 1978 y, en su caso, en qué materias y a través de qué procedimiento. Pero el debate no es nuevo, ni propio de estos tiempos de la llamada «nueva política». Ya se planteó con cierta intensidad durante los primeros años de este siglo. En 2005 el entonces Gobierno socialista solicitó un informe al Consejo de Estado sobre la posibilidad de realizar algunas modificaciones a la Constitución. En aquel momento, el marco de una hipotética revisión constitucional se circunscribió a los siguientes temas: la supresión de la preferencia del varón en la sucesión a la Corona, la recepción en el texto del proceso de construcción de la Unión Europea, la inclusión de la denominación de las Comunidades Autónomas y la reforma del Senado ${ }^{2}$. La coyuntura política de aquellos años, caracterizada por la imposibilidad de pactos y acuerdos entre el Gobierno y la oposición, cercenó cualquier paso en esta dirección. Hoy, las reformas constitucionales que se demandan desde diferentes sectores parecen ser de mucho mayor calado. Algunas afectan a materias tan relevantes como la estructura territorial del Estado o la protección de derechos sociales; materias que forman parte del núcleo definitorio del texto constitucional vigente y que, de llegar a reformarse, podrían suponer una rectificación de lo aprobado en 1978.

A la dificultad que en términos políticos supone toda reforma constitucional, en el caso español debe sumarse la poca fortuna que tuvo el constituyente de 1978 a la hora de regular su procedimiento. La característica principal es que esta cuestión se aborda en dos artículos (en vez de hacerlo en un único artículo), estableciéndose así dos vías de reforma (en vez de una única vía). Por un lado, la del art. 167, para la reforma parcial del texto, que requiere una mayoría cualificada de tres quintos en Congreso y Senado (si en este no se obtiene la mayoría cualificada, sino tan solo mayoría absoluta,

1 Este trabajo ha sido elaborado en el marco del proyecto de I+D+I del Ministerio de Economía y Competitividad titulado «Reforma constitucional: problemas filosóficos y jurídicos» (DER2015-69712-C2-2-R) (MINECO/FEDER, UE).

2 El informe se encuentra disponible en http://www.consejo-estado.es/pdf/modificaciones\%20constitucion \%20esp.pdf (fecha de consulta: 6 de septiembre de 2016). 
entonces sería necesaria una mayoría de dos tercios en el primero), más su aprobación en referéndum si así lo solicita la décima parte de los miembros de cualquiera de las dos cámaras. Por otro lado, la del art. 168, para la revisión total o del «núcleo duro» del texto constitucional (título preliminar, derechos fundamentales y Corona), que requiere la aprobación del principio de reforma por dos tercios de cada Cámara, la inmediata disolución de las Cortes y celebración de elecciones, la ratificación de la reforma por las nuevas Cámaras, la aprobación del nuevo texto por dos tercios de ambas y, finalmente, su ratificación mediante referéndum ciudadano.

Además de generar problemas de carácter lógico (la famosa «paradoja de Ross») y filosófico-político (hacer residir el poder de reforma constitucional en dos artículos), este doble procedimiento impide la consideración de la Constitución como un todo. En efecto, pareciera que existen compartimentos estancos dentro de ella, de manera que resulta posible la reforma concreta de alguno de aquellos sin que ello afecte al resto. Así sucedió, sin ir mas lejos, en la reforma del art. 135: fue realizada por la vía del art. 167, cuando hay argumentos para sostener la tesis de que la introducción en el citado art. 135 del principio de estabilidad presupuestaria y la regla de prioridad absoluta del pago de la deuda y sus intereses afecta de forma decisiva a la cláusula del Estado social, contenida en el art. 1 de la Constitución. Cláusula cuya reforma requeriría la vía agravada del art. 168.

\section{LA PROPUESTA DE FRANCISCO LAPORTA}

Otro problema detectado por la doctrina consiste en la excesiva complejidad del procedimiento de reforma diseñado en el art. 168. Ciertamente justificada cuando se trata de modificar cuestiones centrales en el diseño constitucional - como por ejemplo la forma de Estado- o de iniciar una revisión total del texto, esta complejidad se convierte en un auténtico obstáculo a la hora de acometer reformas que no suponen un cuestionamiento de sus pilares centrales y que, de existir acuerdo político al respecto, podrían acometerse con relativa sencillez. Pero el tenor literal del art. 168 impide esto último. Este podría ser el caso de reformas puntuales como aquellas sobre las que se consultó al Consejo de Estado (por ejemplo, la destinada a eliminar esa discriminación por razón de sexo presente en el art. 57.1, el que regula la sucesión a la Corona). De no tener que aplicarse este procedimiento, quizá resultaría más sencillo realizar reformas de este tipo.

Sobre este punto LAPORTA — quien se suma a la opinión doctrinal mayoritaria a la hora de considerar la fórmula del art. 168 como «engorrosa» e «innecesaria»- elaboró ya en 2004 una propuesta para evitar o aligerar tal complejidad ${ }^{3}$. En su opinión, el art. 168 puede y debe ser interpretado en el sentido de que solo se requeriría seguir la vía trazada por él cuando se revise toda la Constitución, o cuando la reforma afecte

3 Vid. «Las dos vías para la reforma de la Constitución», Claves de Razón Práctica, núm. 145, 2004, 14-23. En realidad, son dos las propuestas formuladas por LAPORTA, pero una de ellas quedará al margen de estas líneas, dado que su propio autor parece haber renunciado a ella por su excesivo formalismo. Se trata de la propuesta de reformar el art. 168 - con el objeto de crear un nuevo procedimiento menos «engorroso»— por la vía del art. 167, dado que el tenor literal de ambos artículos no lo impediría. 
a todo el título preliminar, o a toda la sección primera del capítulo segundo del título primero (los derechos fundamentales), o a todo el título segundo. Es decir, cuando la revisión afecte a los títulos o secciones completas mencionadas en el art. 168. Por el contrario, cuando se trate de reformas parciales o puntuales de dichos títulos o secciones, bastará con seguir la vía ordinaria fijada en el art. 167.

Dos son los argumentos esgrimidos en apoyo de esta interpretación. En primer lugar, que al tratarse de un procedimiento extraordinario, frente al ordinario del art. 167, debe ser interpretado restrictivamente. Y la de LAPORTA es una forma de hacerlo así. En segundo término, que no fue voluntad del constituyente introducir cláusulas de intangibilidad en el texto constitucional y una interpretación no restrictiva del art. 168 convierte de facto a este artículo en una de ellas. Como advierte LAPORTA, inicialmente no había dos procedimientos de reforma en el anteproyecto de Constitución presentado por la ponencia, sino que fueron las exigencias y vericuetos del tan traído y llevado «consenso» constitucional los causantes de una solución final tan defectuosa técnicamente como problemática la hora de ser aplicada.

En suma, una interpretación como la diseñada por LAPORTA tendría la virtud de — dicho en sus propios términos- «desactivar el cerrojo que supone el artículo 168». La otra supondría, de hecho, arrastrar toda reforma constitucional al procedimiento rígido, dado que siempre podría argüirse que «afecta» a derechos fundamentales, a principios constitucionales centrales o a cuestiones referidas en el título preliminar, como por ejemplo a la cláusula del Estado social contenida en el art. 1. Como el propio LAPORTA señala, la tesis de la interpretación restrictiva encuentra apoyo en el Tribunal Constitucional cuando, en su Declaración de 1 de julio de 1992, convalidó la reforma del art. 13.2 de la Constitución por la vía del art. 167. Téngase en cuenta que la reforma afectaba directamente al art. 23, que es uno de los sometidos a la vía del art. 168 (derecho de sufragio activo y pasivo). Aun así, el TC rechazó que la reforma debiera haberse llevado a cabo por el procedimiento agravado. Más recientemente, el Tribunal ha vuelto a pronunciarse en defensa de la interpretación restrictiva, volviendo a dar la razón a las tesis de LAPORTA. En su Auto 9/2012, de 13 de enero, consideró ajustada a la Constitución la reforma del art. 135 por la vía del art. 167, al rechazar toda conexión entre el contenido de aquel artículo y la cláusula del Estado social del título preliminar de la Constitución, cuya reforma requeriría la vía del art. 168. Es, como sostiene LAPORTA, una forma de entender restrictivamente lo dispuesto en este último artículo.

Además de ser muy rigurosa desde el punto de vista teórico, la propuesta de LAPORTA tiene el acierto de situar el centro de la cuestión en el terreno interpretativo. Como todas las disposiciones normativas, las constitucionales requieren de la labor del intérprete a la hora de dotarlas de contenido. En esta labor entran en juego aspectos subjetivos, como por ejemplo la ideología y los «anteojos epistemológicos» del intérprete, y aspectos convencionales como el sentir o concepción mayoritaria de la cultura jurídica. Todos estos elementos entrarán en juego a la hora de dotar de significado o interpretar la disposición constitucional del art. 168, es decir, en el momento de responder a la pregunta sobre qué significa «afectar a». Pero lo harán también a la hora de determinar cuándo se trata de una reforma puntual o concreta de la Constitución, aquella que no compromete su núcleo central, y cuándo por el contrario se está ante 
una reforma que va más allá, cuestionando o rectificando el sentido general del texto de 1978.

Surge pues una cuestión de tipo interpretativo, relativa a la posibilidad de conocer cuáles son los elementos que conformarían esa identidad, espíritu o núcleo central de la Constitución de 1978. Elementos cuya modificación, eliminación o sustitución por otros supondría una alteración sustantiva del texto constitucional. En mi opinión, hay buenas razones para pensar que estos elementos son los señalados en el art. 168. Por ello los colocó ahí el constituyente y los rodeó de una rigidez máxima como protección frente a su reforma. Tanto el Tribunal Constitucional como la cultura jurídica mayoritaria vendrían a corroborar esta respuesta. En consecuencia, la modificación de cualquiera de los puntos señalados en el art. 168 requiere la vía agravada contemplada en este artículo.

En este sentido, la respuesta de LAPORTA a esta cuestión parece estar muy condicionada por el tenor de los elementos que se pretendían reformar en 2004. Aspectos que, sin dejar de ser importantes, no comprometían el «espíritu» de la Constitución y, además, contaban con un cierto consenso político y académico. Bajo tales circunstancias, se entiende con claridad una propuesta como la de LAPORTA, que buscaba evitar el «engorroso» procedimiento del art. 168 para cuestiones tan puntuales y consensuadas como las ya citadas. Además, tampoco cabe olvidar que una de ellas incumbe a una cuestión tan delicada en nuestra historia moderna como es la de la monarquía. Si para eliminar la discriminación que actualmente contempla el art. 57.1 entre otros requisitos hay que ratificar su reforma mediante referéndum ciudadano, podría volver a abrirse la caja de los truenos que supone la reivindicación republicana. En tal caso, ¿conviene preguntar al pueblo cuando no se tiene la certeza de lo que va a responder?

En consecuencia, y debido a su cariz profundamente interpretativo, el reto de la propuesta de LAPORTA consiste en determinar hasta dónde estaría dispuesto a aplicarla, es decir, qué reformas —además de la ya citadas - serían susceptibles de la interpretación restrictiva y cuáles, en cambio, requerirían del procedimiento agravado del art. 168 en toda su literalidad. Veámoslo con un ejemplo concreto. Una de las demandas que están encima de la mesa es la de dotar de mayor protección constitucional al derecho a la vivienda, hoy fuera del «núcleo duro» de la vigente Constitución. Su entrada al mismo requeriría su inclusión en la sección primera del capítulo segundo del título primero del texto, es decir, una reforma por la vía agravada del art. 168. ¿Aceptaría LAPORTA que este supuesto no compromete la identidad del texto constitucional y que, por tanto, podría ser objeto de su interpretación restrictiva de este artículo? $\mathrm{O}$, en cambio, ¿'sostendría que equiparar en cuanto a su protección el derecho a la vivienda a otros como el derecho a la vida y la libertad de expresión supone una rectificación sustancial de lo decidido por el constituyente y que, así pues, se requiere la puesta en marcha de la vía del art. 168 en su interpretación no restrictiva?

Sin embargo, en un trabajo publicado más de diez años después del analizado en estas líneas, LAPORTA parece dejar de lado este debate interpretativo ${ }^{4}$. En su opinión, el deterioro y desconfianza institucional sufridos durante estos años hacen necesaria una reforma constitucional profunda y de calado, porque de lo contrario la Constitu-

\footnotetext{
4 Vid. «La encrucijada constitucional», Claves de Razón Práctica, núm. 241, 2015, 29-37.
} 
ción o «empezará a deslizarse hacia la condición de papel mojado», o será objeto de «sucesivas mutaciones mediante interpretaciones constructivas» por parte del Tribunal Constitucional. Para evitar las negativas consecuencias de ambas posibilidades, solo existe una solución: «Convocar nuevamente un gran acuerdo entre todos».

De esta nueva propuesta lanzada por LAPORTA surge con toda su intensidad un problema adicional, esta vez de índole conceptual o dogmático, ya esbozado en estas línas. Esta reforma de calado, cha de entenderse como una reforma constitucional o más bien como la instauración de una nueva Constitución? Responder de una u otra forma no es algo exento de consecuencias. Si la respuesta es la segunda, es decir, si se sostiene que alterar los elementos centrales de la Constitución de 1978 (como por ejemplo configurar un Estado federal frente al actual Estado de las autonomías) significa crear una nueva Constitución, entonces de poco valdrían la rigidez y cautelas establecidas en el vigente texto constitucional, dado que estaríamos ante un acto no de reforma del mismo, sino de auténtica ruptura constitucional. Y en este caso, ¿tendría sentido alegar en toda su literalidad el art. 168 cuando es el tenor general del texto constitucional el que se impugna?

\section{UNA PREGUNTA FINAL A LIBORIO HIERRO}

Sobre la cuestión de la reforma constitucional también se ha pronunciado HIERRO. En su último libro afirma explícitamente la necesidad de llevar a cabo una reforma del art. 168 con el objeto de aliviar la rigidez del texto constitucional español ${ }^{5}$. Esta propuesta se enmarca en el alegato que el autor hace en favor del llamado «constitucionalismo débil», caracterizado — entre otros aspectos- por defender una mayor facilidad para la reforma de la Constitución, estableciendo mecanismos que permitan que la última palabra al respecto la tenga la mayoría parlamentaria y/o la ciudadanía tras un debate público. En su opinión, las cuestiones controvertidas —y las relativas a la interpretación de las disposiciones constitucionales sin duda lo son— deben quedar sometidas, además de a un control jurisdiccional caracterizado por el principio de autorestricción judicial que se deriva de la presunción de constitucionalidad de las leyes, a que la última palabra corresponda siempre a la mayoría democrática. Y de ahí, en definitiva, la necesidad de articular la necesaria rigidez constitucional de una forma tal que no impida esto último.

Por tanto, HIERRO coincide con LAPORTA en el diagnóstico sobre el actual art. 168 y en la necesidad de establecer mecanismos que faciliten la reforma constitucional. Pero, en principio, su tesis no deja traslucir opinión ni valoración alguna sobre la propuesta interpretativa de LAPORTA. De la necesidad de reformar el art. 168 no se deduce ni que admita la interpretación restrictiva de este artículo ni que la rechace. Entonces, ¿cuál es su posición al respecto?

En mi opinión, su adhesión al llamado positivismo ético o normativo ofrecería alguna pista ${ }^{6}$. Como es de sobra conocido, HIERRO es el mayor defensor en nuestra cul-

5 Vid. Los derechos bumanos. Una concepción de la justicia, Madrid, Marcial Pons, 2016, 202-203.

6 En este sentido, vid. su artículo «¿Por qué ser positivista?», Doxa, núm. 25, 2002, 263-302 (esp. 294-299). 
tura iusfilosófica de este tipo de positivismo, el cual avanza un paso más con relación a la clásica tesis positivista de la separación conceptual entre el Derecho y la moral. Arguye HIERRO que la inclusión de principios morales en nuestros sistemas constitucionales supone el riesgo de conceder a poderes constituidos la capacidad de imponer sus valores y creencias morales a la hora de identificar lo dispuesto en las disposiciones constitucionales (algo que ya KELSEN había señalado en los años veinte del siglo pasado). Así pues, separar Derecho y moral es necesario por razones morales: por un lado, para que opciones morales particulares no se impongan a la colectividad por la vía de la interpretación; y por otro, para evitar que el Derecho reemplace a la moral como criterio final de valoración de conductas.

Sin duda, la redacción del art. 168 de la Constitución no contribuye a minimizar estos riesgos. Pero la propuesta de LAPORTA tampoco, porque deja al criterio de órganos como el Parlamento y el Tribunal Constitucional —que son, recuérdese, poderes constituidos- la decisión sobre cuándo una reforma podría ser objeto de la interpretación restrictiva y, por tanto, no someterse a todo el procedimiento detallado en tal artículo. Creo que el poder que tal interpretación concede a tales órganos vendría a ser «insoportable» en términos políticos y morales. Así, en tanto en cuanto no se reforme, el principio de seguridad jurídica aconseja una interpretación rigurosa y no restrictiva de lo dispuesto en el debatido art. 168. Por defender este principio también merece la pena seguir siendo positivista. 